\title{
INFLUÊNCIA DO CULTIVO CONTÍNUO DA CANA-DE-AÇÚCAR EM LATOSSOLOS AMARELOS COESOS DO ESTADO DE ALAGOAS: PROPRIEDADES MICROMORFOLÓGICAS ${ }^{(1)}$
}

\author{
A. J . N. SILVA(2), M. R. RIBEIRO(3), A. R. MERMUT ${ }^{(4)}$ \& M. B. BENKE ${ }^{(5)}$
}

\begin{abstract}
RESUMO
Foram estudados os efeitos do cultivo contínuo da cana-de-açúcar por meio da análise micromorfológica de Latossolos Amarelos argilosos da região dos tabuleiros costeiros do estado de Alagoas, Brasil. Quatro talhões foram selecionados na Usina Caeté, município de São Miguel dos Campos, AL, em janeiro de 1995, sendo um com vegetação nativa (Tn), e os demais cultivados por períodos de dois (T2), dezoito (T18) e vinte e cinco (T25) anos. Os solos foram morfologicamente caracterizados, sendo coletadas amostras indeformadas dos horizontes A, AB e BA de cada perfil, em caixas de Kubiena, para análises micromorfológicas. Foram coletadas amostras para análises de densidade do solo, macroposi dade, carbono orgânico e condutividade hidráulica saturada. Os resultados evidenciam que o uso agrícola dos solos causou mudanças na morfologia do horizonte superficial, com o desenvolvimento de um horizonte Ap, com sensível perda de estrutura. Após um evidente impacto negativo nas propriedades físi cas com o primeiro plantio da cana-de-açúcar, o manejo adotado promoveu uma recuperação parcial da macroporosidade no horizonte superficial após 18 e 25 anos de cultivo. Além da formação i nicial de uma camada compactada nos horizontes Ap e AB, foi observado um adensamento pedogenético natural do solo no BA, acelerado com o cultivo da cana-de-açúcar, pelo preenchimento de poros com argila iluvial. A porosidade total obtida pelo analisador de imagem nas fotografias das lâminas delgadas corrobora uma sensível redução da porosidade no horizonte superficial com a introdução do cultivo. Mostra também que a porosidade do horizonte BA é baixa no perfil com vegetação nativa, comprovando o caráter pedogenético do adensamento desse horizonte. Apesar de não ter sido observado nenhum revestimento nas unidades estruturais em campo, a micromorfologia mostrou pedofeições morfológicas com revestimentos argilosos nos agregados e enchimento de poros com argila iluvial, o que indica a tendência à formação de horizonte B textural com o tempo.
\end{abstract}

Termos de indexação: Latossolo Amarelo argiloso, propriedades físicas, tempo de cultivo, adensamento, coesão, compactação.

\footnotetext{
(1) Parte da Tese de Mestrado do primeiro autor, apresentada à Universidade Federal Rural de Pernambuco - UFRPE. Trabalho apresentado no XIII Congresso Latino-Americano de Ciência do Solo, Solo-Suelo, Águas de Lindóia, SP, agosto de 1996. Recebido para publicação em março de 1997 e aprovado em junho de 1998.

(2) Engenheiro-Agrônomo, aluno de Pós-Graduação em Ciência do Solo, UFRPE. Rua Bom J ardim, no 125, BL 1, apto 303, J ardim Brasil I, CEP 53230-520, Olinda (PE).

(3) Professor do Departamento de Agronomia, UFRPE. R. Dom Manuel Medeiros s/n, CEP 52171-900 Recife (PE). Bolsista do CNPq.

(4) Professor do Departamento de Solos, Universidade de Saskatchewan, Saskatoon, Saskatchewan, Canadá, S7N-5A8.

(5) Professora do Departamento de Agronomia, UFRPE. CEP 52171-900 Recife (PE).
} 


\title{
SUMMARY: INFLUENCE OF CONTINUOUS SUGARCANE CROPPING ON THE MICROMORPHOLOGICAL PROPERTIES OF YELLOW LATOSOLS IN ALAGOAS STATE, BRAZIL
}

\begin{abstract}
Theeffects of continuous sugarcanecropping on theproperties of a dayey Yell low Latosol werestudied in theregi on of the Low Coastal Tablel ands of Alagoas State, Brazil. Four sites were selected at Caeté mi II, São Miguel dos Campos, AL, involving a nativeforest (Tn) and sugarcane fields cultivated for periods of two (T2), eighteen (T18) and twenty-five (T25) years. The soi ls were morphol ogically characterized and undisturbed samples of the $A, A B$, and BA horizons of each profilewerecollected for micromorphological analysis. Theresults showed that agricultural use promoted morphological changes with the devel opment of an Ap horizon with loss of original structure After an evident negative impact on physical properties after thefirst crop (profileT2), management practices promoted a partial increase in the macroporosity of the surface horizon after 18 and 25 years. Besides the devel opment of compaction in the $A p$ and $A B$ horizon with cultivation, a natural pedogenetic denselayer was observed in theBA horizon. This densification is increased with agricultural use, dueto thefilling of pores with illuvial day. Total porosity measurements obtained by imageanalysis of thin secti ons reveal ed decreasing porosity at thesurfacehorizon with thefirst cultivation. This reduction, however, did not increasewith conti nuous cropping. Theimageanalysis also showed that the natural porosity of the BA horizon is very small even in the profile under nativeforest, indicating pedogenic origin of the densification of this horizon. Although clay coatings were not observed in the field, micromorphology showed pedofeatures with clay coatings in peds and filling of pores with illuvial clay. This observation and the significant increase of thetextural gradient all suggest a tendency to theformation of an argillichorizon with time
\end{abstract}

Index terms: ClayeyYel low Latosol, physical properties, cropping time, densification, cohesion, compactness.

\section{INTRODUÇÃO}

Grande número detrabal hos e pesquisas tem sido realizado para avaliar os efeitos do cultivo e práticas de manejo nas propriedades morfológicas, químicas, físicas e biológicas dos solos. Segundo Drees et al. (1994), as mudanças nessas propriedades, embora possam ser mensuradas, são, em grande parte, conseqüência de alterações na estrutura do sol o em microescala. No entanto, poucos estudos micromorfológicos têm sido efetuados para avaliar alterações no tamanho das partículas, orientação dos poros e agregados.

Segundo Schaefer et al. (1995), o conhecimento das características pedológicas edo arranjo estrutural micromorfológico em sol os brasileiros é ainda incipiente, quando comparado com a grande quantidade de estudos macromorfológicos. Uma das utilidades mais importantes da micromorfologia refere-se à verificação de possíveis mudanças na morfologia do solo causadas pelo cultivo contínuo. No início da segunda metade deste século, já havia indícios das possíveis aplicações da micromorfologia para estudar essas alteraçõ̃es. Cagauan \& Uehara (1965), trabal hando com L atossol os do Hawai, encontraram uma relação positiva entrea estabi lidade deagregados desses sol os e a intensidade de anisotropia.
Mais recentemente, Cerri et al. (1991) estudaram as mudanças nas propriedades de um L atossol o após o desmatamento ecultivo por 12 e 50 anos com canade-açúcar. A comparação entre sol os cultivados e sob mata nativa mostrou que as modificações microestruturais afetaram principalmente a parte superior do perfil do solo. Houve formação de estrutura e porosidade próprias aos horizontes cultivados, decorrente da fragmentação e compactação dos horizontes superficiais, onde os microvazios de diâmetro entre 5 a 30 micrômetros, inicialmente policôncavos e comunicantes no solo virgem, tornaram-se planares e descontínuos após o cultivo.

Ainda com referência aos Latossol os, Costa Lima \& Costa Lima (1995) estudaram o efeito do cultivo contínuo da cana-de-açúcar everificaram al terações na contextura plásmica e na morfologia dos poros até a profundidade de $0,30 \mathrm{~m}$. As contexturas mullgranói dicas, predominantes nas camadas superiores dos Latossol os argilosos sob mata nativa, al teraramse para porfírica com cavidades ou fendas após o cultivo, coma perda da matéria orgânica superficial. Nos Latossolos de textura muito argilosa, observaram-se modificações na dimensão, coalescência das unidades estruturais, sem, porém, modificar o tipo de trama original do solo virgem. 
Alguns estudos mostraram que as mudanças ocorridas na micromorfologia dos sol os podem variar de acordo com os diversos sistemas de manejo aplicados ao solo, exercendo importante papel nas suas características estruturais (Pawluk, 1980; Pagliai et al., 1983; Shi pital o\& Protz, 1987). Segundo Drees et al. (1994), considerando a crença de que os sistemas de cultivo mínimo oferecem melhorias ao solo para o crescimento das plantas, é essencial melhor entendimento das mudanças na estrutura do solo induzidas por tais práticas de cultivo conservacionista. As aval iações mi cromorfológicas do solo sob esses diferentes sistemas de manejo podem proporcionar informações valiosas sobre as mudanças estruturais do solo.

No Brasil, poucos trabalhos têm estudado o arranjo estrutural e as características pedológicas em nível micromorfológico e, na maioria das vezes, isto tem sido feito em estudos de gênese e classificação de solos. Raros são os trabalhos que utilizam as avaliações micromorfológicas para identificar as mudanças provocadas pelo cultivo contínuo nas propriedades do solo, o que poderia proporcionar mel hor entendimentonas modificações estruturais, por meio da observação de detal hes nãomensuráveis em macroescala.

Sendo assim, o objetivo deste trabalho foi determinar as possíveis modificações nas propriedades micromorfológicas de Latossolos Amarel os argilosos cultivados com cana-de-açúcar, com o intuito de obter informações indispensáveis à melhor definição das práticas de manejo, visando manter ou recuperar a sua capacidade produtiva.

\section{MATERIAL E MÉTODOS}

O trabal ho foi desenvol vido em áreas localizadas na Usina Caeté, no município de São Miguel dos Campos, microrregião homogênea $\mathrm{n}$ o 119 do litoral de Alagoas. Com base em levantamento pedológico detal hado feito na usina Caeté em 1993, foram selecionados quatro perfis de Latossol os Amarelos, representativos de áreas com vegetação nativa, e cultivados com cana-de-açúcar, por diferentes períodos de tempo.

As parcelas com diferentes tempos de cultivo foram comparadas entre si e em relação a uma testemunha absoluta, representada pelo solo em condições naturais (vegetação nativa). Os perfis receberam as seguintes identificações: Tn - solo em condição natural (vegetação nativa); T2 - solo com 2 anos de cultivo; T18 - solo com 18 anos de cultivo e T25 - solo com 25 anos de cultivo.

Todos os perfis ocupavam uma mesma posição topográfica de topo plano de baixo platô costeiro. No primeiro plantio e a cada seis anos, quando da renovação, foram feitas duas gradagens pesadas e abertura dos sulcos com sulcador. Fez-se também, nessa ocasião, uma adubação N-P-K de acordo com a análise do sol o. Anual mente, for am admi nistradas adubações de cobertura, feitas com base na análise do solo, que indicaram, em média, cerca de $495 \mathrm{~kg}^{\mathrm{k}} \mathrm{h}^{-1}$ da fórmula 16-00-24, além de uma a duas limpas e aplicação de herbicidas. Também foram aplicados cerca de $400 \mathrm{~m}^{3}$ ha-1 de vinhaça.

Análises micromorfológicas - Após a descrição morfológica dos perfis, procedeu-se à coleta de amostras indeformadas nos três primeiros horizontes de cada trincheira, com auxílio de caixas de Kubiena com dimensões de 10,0 x 6,5 x 5,0 cm, para posterior confecção das lâminas del gadas.

As lâminas foram confeccionadas no Laboratório de Micromorfologia da Universidade Federal Rural de Pernambuco. As amostras indeformadas foram impregnadas com resina de poliéster, segundo método descrito por J ongerius \& Heintzberger (1963) e Fitzpatrick (1984), e desbastadas com o sistema Warning da Westinghouse. As amostras foram coladas em lâminas de vidro e seccionadas com auxílio da máquina de corte Raytech e submetidas a três pol imentos com abrasivos deóxi do dealumínio Buehller, de granulações 25, 9,5 e $5 \mu \mathrm{m}$. Os polimentos foram feitos em sistema automático PM2A da Logitech, até ficarem com espessura entre 30-35 micrômetros. Após atingirem a espessura ideal, verificada com auxílio do microscópio petrográfico, as lâminas foram limpas em ultra-som e cobertas com lamínulas para posterior análise micromorfológica (Murphy, 1986).

As descrições das lâminas delgadas foram realizadas no Departamento de Ciência do Solo da Universidade deSaskatchewan, Canadá, segundo os conceitos de Brewer (1964), J ongerius et al. (1972), Stoops \& J ongerius (1975) e Bullock et al . (1985). As adaptações dos termos para o português foram feitas deacordo com Lima et al. (1985) eSantos et al. (1991).

As micrografias e a porosidade total analisadas foram obtidas na Divisão de Serviços Audiovisuais da Universidade de Saskatchewam. A captação da imagem da fotografia para o computador foi feita através de "scanner" e depois processada pelo programa Adobe Photoshop versão 2.51 para Macintosh. A porosidade total analisada foi obtida por meio de analisador de imagem, utilizando o programa Ultimage versão S1.41 Graftek 1988/1990 para Macintosh. As abreviaturas XPL e 1/2 XPL, constantes nas legendas das micrografias, significam, respectivamente, nicóis cruzados enicóis parcialmente cruzados.

Análises físicas e quími cas - As anál ises físicas equímicas foram feitas nos Laboratórios de Física e de Química do Solo da Universidade Federal Rural de Pernambuco, respectivamente, segundo método descrito no Manual de Métodos de Análise de Solo (EMBRAPA, 1979). As variáveis determinadas foram: densidade do solo, com anel volumétrico; 
porosidade total cal culada, segundo Vomocil (1965); macroporosidade, pela expressão proposta por Grohmann (1960); água disponível e condutividade hidráulica saturada, em amostras indeformadas, por meio de permeâmetro descrito por Lima (1986) e conforme a equação de Darcy-Williams, descrita por Klute \& Dirksen (1986). O carbono orgânico foi obtido por volumetria, com oxidação pel o bicromato de potássio.

Tratamento estatístico - As variações da porosidade do solo com o tempo de cultivo e com a profundidade foram estudadas por meio de um delineamento intei ramentecasualizado em esquema fatorial $4 \times 3$, segundo Silva \& Silva (1982), correspondente a quatro diferentes tempos de cultivo, três profundidades e com três repetições. Os tratamentos de interesse estudados foram determinados na elaboração do experimento e são considerados como fatores fixos.

Quando o tempo de cultivo e, ou, profundidade, bem como a interação entre eles, foram significativos no teste $F$, a comparação das médias foi feita pelo teste de Tukey a 5\%, para cada caso, usando-se o "software" Sanest (Zonta \& Machado, 1980).

\section{RESULTADOS E DISCUSSÃO}

A figura 1 ilustra as fotografias das seções delgadas e dá um aspecto visual dos horizontes superficiais e subsuperficiais dos quatro perfis estudados. A observação visual das lâminas ilustra a redução da porosidade no horizonte Ap do perfil com dois anos de cultivo (T2) em rel ação ao horizonte A do solo sob mata nativa (Tn). O horizonte A do perfil Tn mostra forte pedali idade com o material do solo dividido em unidades (pedes) circundadas por poros. N o primeiro plantio da cana-de-açúcar (perfil T2), os pedes e os poros de empacotamento complexo do horizonte Ap são destruídos. Essa redução, no entanto, não tende a aumentar com o tempo de cultivo (perfis T18 e T25). Nos horizontes subsuperficiais, a redução da porosi dade com o tempo de cultivo é menos evidente.

A contextura matricial do solo apresentou-se semel hante nos quatro perfis estudados, sendo predominantemente enáulica, nos horizontes Ap e AB (Figuras 2, 3 e 4), e porfírica do tipo aberto, nos horizontes BA (Figura 5). A matéria orgânica está presente em diferentes estádios de decomposição
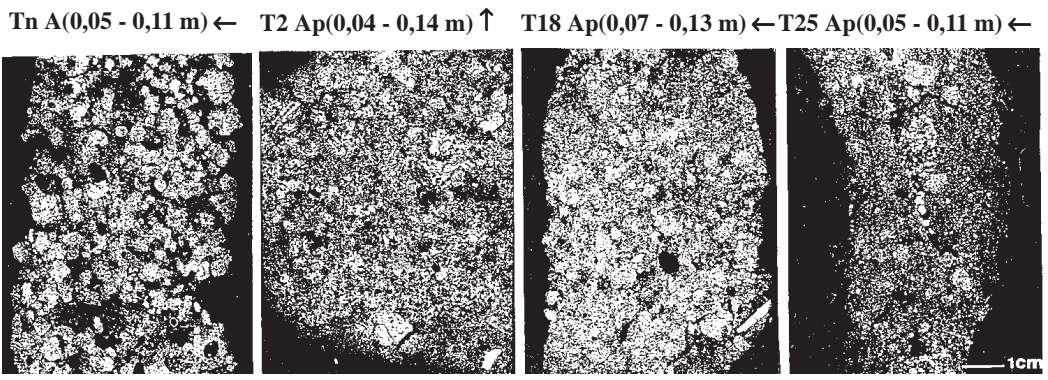

Tn AB(0,20 - 0,30 m) $\uparrow$

$\mathrm{T} 2 \mathrm{AB}(0,21-0,31 \mathrm{~m}) \uparrow$

$\mathrm{T} 18 \mathrm{AB}(0,25-0,35 \mathrm{~m}) \uparrow \mathrm{T} 25 \mathrm{AB}(0,21-0,31 \mathrm{~m}) \uparrow$
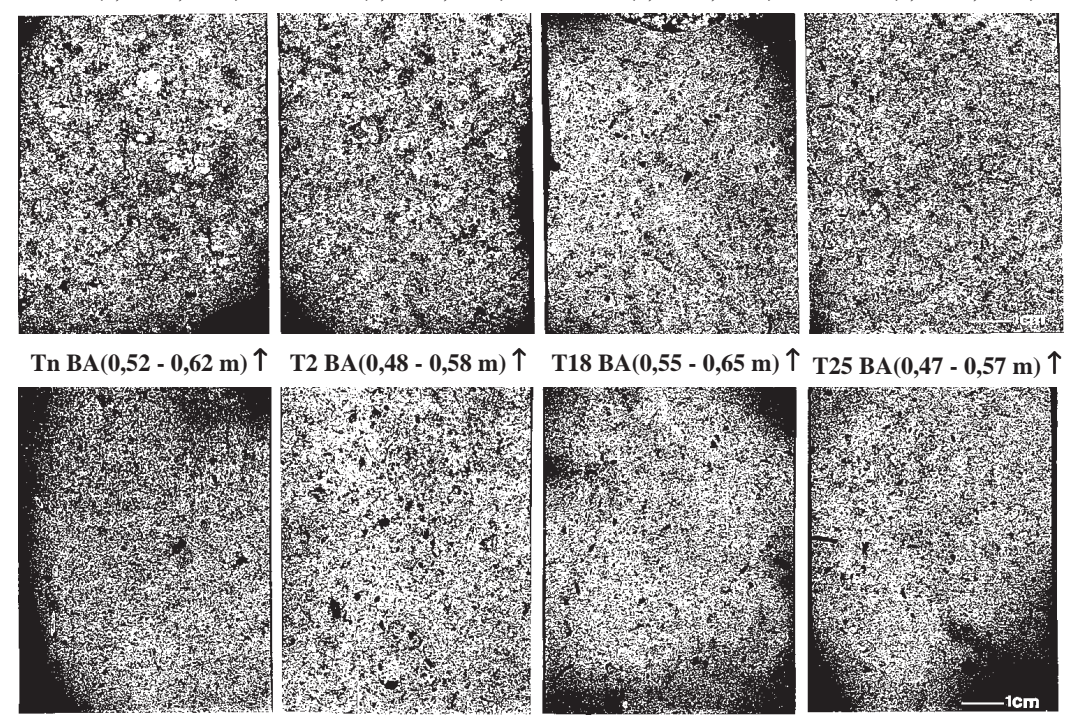

T18 BA $(0,55-0,65 \mathrm{~m}) \uparrow \operatorname{T25} \mathrm{BA}(0,47-0,57 \mathrm{~m}) \uparrow$
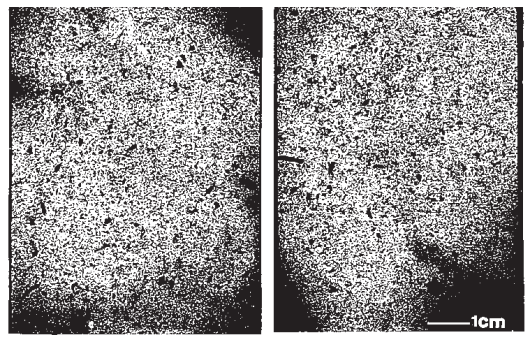

Figura 1. Aspecto macroscópico da porosidade dos horizontes Ap e subsuperficiais dos perfis sob cultivo (T2, T18 e T25) em relação aos horizontes A e subsuperficiais do perfil sob mata nativa (Tn). 
(Figura 6), influenciando a cor da matriz no horizonte $A$, tanto no perfil sob vegetação nativa, como também nos cultivados, por causa do sistema radicular fasciculado da cana-de-açúcar. Observamsetambém, nesses últimos, fragmentos carbonizados, o que evidencia o efeito das quei madas nesses solos.

A influência da intensa atividade biológica é evidenciada na estrutura dos horizontes em todos os perfis, como é observado no horizonte $A$ do solo sob mata nativa (Figura 6), horizonteAp do sol o com dezoito anos de cultivo (Figura 2) e horizonte BA do solo com 25 anos de cultivo (Figura 5). O horizonte A do perfil sob mata nativa (Figura 6) e os horizontes Ap dos solos cultivados apresentam numerosos microagregados granulares (10-50 $\mu \mathrm{m})$, de formato arredondado, semelhantes a pelotas fecais, caracterizando uma estrutura micropédica, que, segundo Stoops \& Buol (1985), são típicas de al guns Oxissolos. Tais microagregados granulares (Bullock et al., 1985) aparecem de forma isolada, ou ligados uns aos outros, formando agregados maiores, conferindo ao sol o uma contextura básica complexa do tipo matrigrânica/matrigranóidica (Brewer \& Pawluk, 1975).

A análise micromorfológica mostra que os horizontes $A B$ dos perfis sob cultivo sofreram maior compactação que o horizonte $A B$ do solo sob vegetação nativa. I sto é observado nitidamente pela redução da porosidade nos horizontes $A B$ dos perfis T2 (Figura 3), T18 (Figura 7) e T25 (Figura 8), em relação ao horizonte $A B$ do perfil Tn (Figura 4).

Nota-se também que, no solo sob mata nativa, os microagregados ligados uns aos outros formam uma rede de poros interagregados comunicantes

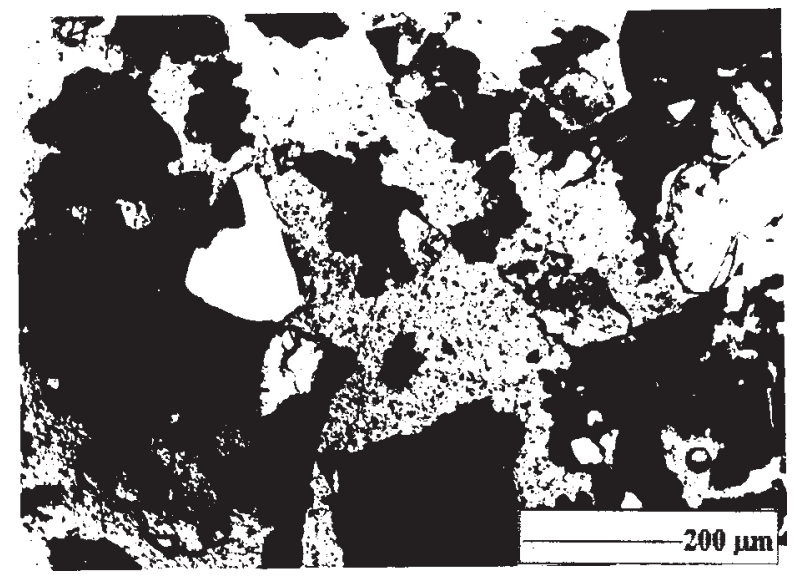

Figura 2. Horizonte Ap do perfil sob cultivo há 18 anos, mostrando microagregados arredondados isolados e ligados uns aos outros, constituindo uma microestrutura com forte influência da atividade biológica (1/2 XPL).

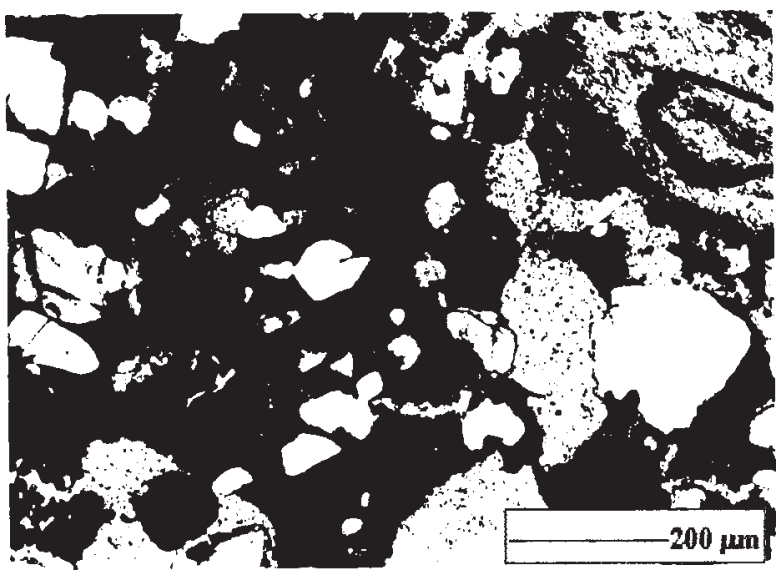

Figura 3. Contextura matricial enáulica do horizonte AB do perfil sob cultivo há dois anos (XPL).

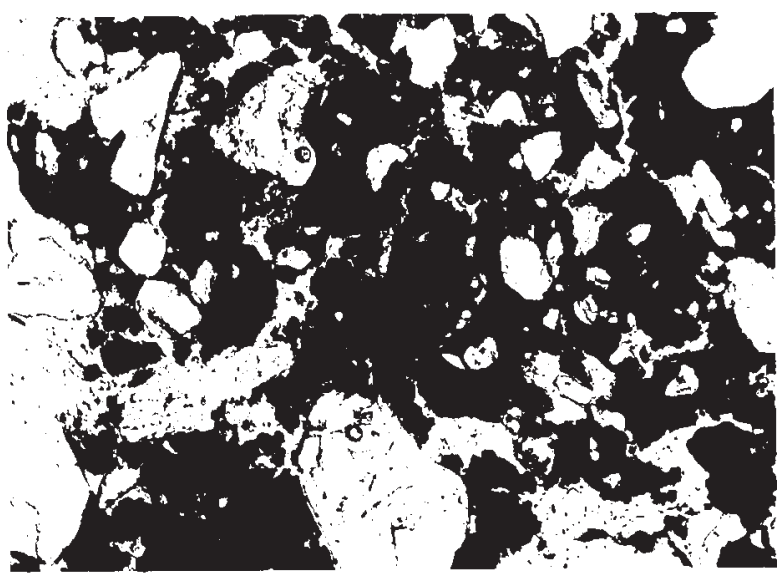

Figura 4. Microagregados formando rede de microporos comunicantes no horizonte $A B$ do perfil sob mata nativa (XPL).

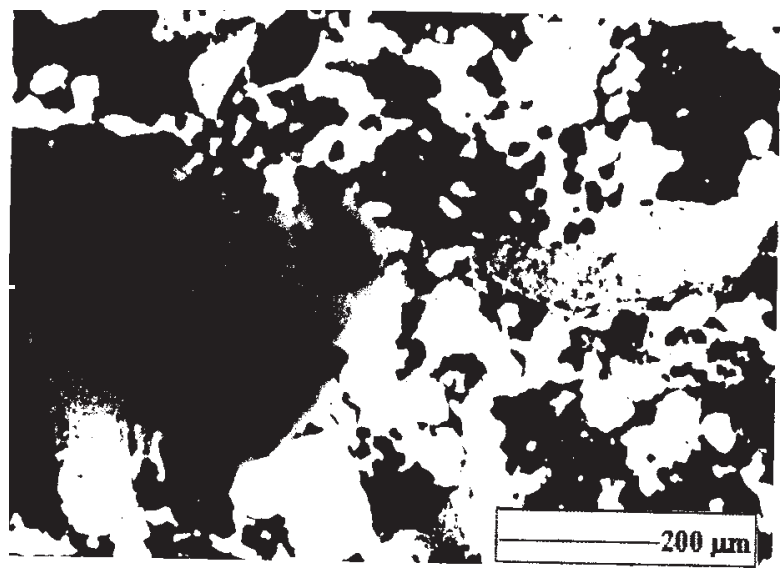

Figura 5. Atividade biológica e contextura matricial porfírica no horizonte BA do perfil com 25 anos de cultivo (1/2 XPL). 


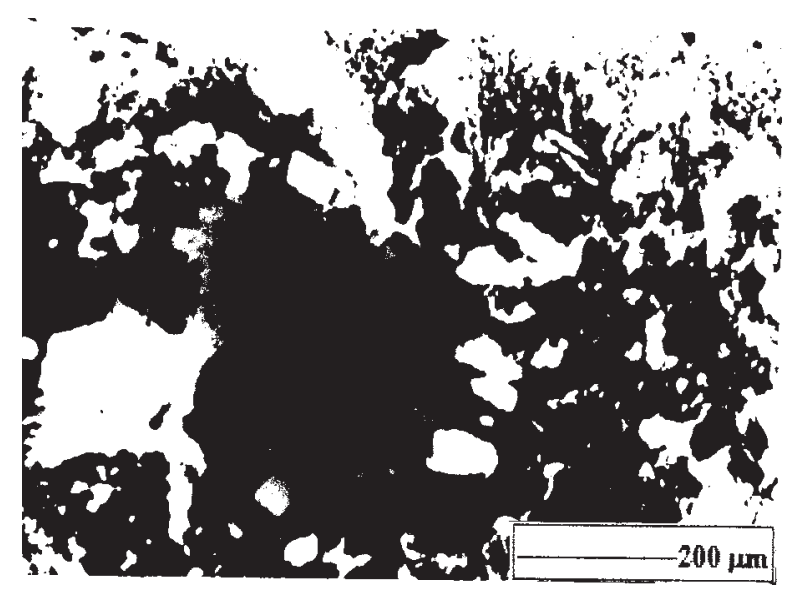

Figura 6. Matéria orgânica em diver sos estádios de decomposição no horizonte A do perfil sob mata nativa (XPL).

(Figura 4). Após 18 e 25 anos de cultivo, essa rede de microvazi os mostra mudanças de forma, devidas à movimentação do solo, transformando-se em poros mais ou menos descontínuos, e numerosas microfissuras não-comunicantes (Figuras 7 e8). Esse novo conjunto de poros não-contínuos comporta-se como reservatórios de água, mantendo-se parcialmente saturados. A não-continuidade desses microvazios na estrutura dos horizontes $A, A B$ eBA dos perfis T18 eT25 é evidenciada pelo aumento da água disponível retida nesses poros (Quadro 1), pois, caso contrário, eles se esvaziariam mais facilmente sob baixas tensões, como ocorre nos perfis Tn eT2. Observa-se, ainda, que o aumento expressivona água disponível não ocorre nos horizontes inferiores $\mathrm{Bw}_{1}$ e $\mathrm{Bw}_{2}$ (Quadro 1), mostrando que a mudança microestrutural ocorreu apenas nos primeiros horizontes dos perfis T18 eT25, mais influenciados pela movimentação do sol o sob cultivo.

Os macroagregados orgânicos, comuns no horizonte superficial do perfil sob mata nativa, são ilustrados na figura 9, observando-se poros largos ao seu redor, que evidenciam a estrutura favorável desses solos em condições naturais.

Nos horizontes superficiais dos sol os cultivados, os agregados são mistos ou constituídos de plasma inorgânico revestidos de matéria orgânica. Esses agregados são claramente destruídos no horizonte Ap do perfil T2 (Figura 10), ocasionando drástica redução da macroporosidade, porosidade total cal culada e condutividade hidráulica saturada, bem como aumento da densidade do solo (Quadro 1).

A partir dos 18 anos de cultivo (Figura 11), al guns macroagregados são observados no horizonte Ap, refletindo uma recuperação da estrutura granular, em relação ao perfil T2, o que ficou evidenciado estatisticamente pelo aumento da condutividade hidráulica saturada, porosidade total calculada e macroporosidade (Quadro 1). Essa recuperação se deve, provavel mente, ao manejoadotado eao sistema radicular fasciculado da cana-de-açúcar, que resultou num aumento do conteúdo de matéria orgânica a níveis próximos aos do perfil sob vegetação nativa (Quadro 2), promovendo uma reestruturação do solo, a exemplo deoutras gramíneas (Ortolani et al., 1991).

Segundo alguns autores (Tisdall \& Oades, 1982; Oades, 1984), a estabilidade dos microagregados é pouco influenciada por diferentes práticas agrícolas e por mudanças no conteúdo da matéria orgânica do solo causadas pelo cultivo, sendo, portanto, relativamente permanentes ou estáveis. Com relação aos macroagregados, no entanto, a estabilidade destes é mais suscetível de ser influenciada pelo manejo do solo, aumentado em áreas de pastagens, e diminuindo quando o solo é arado, caso não haja um retorno orgânico ao solo.

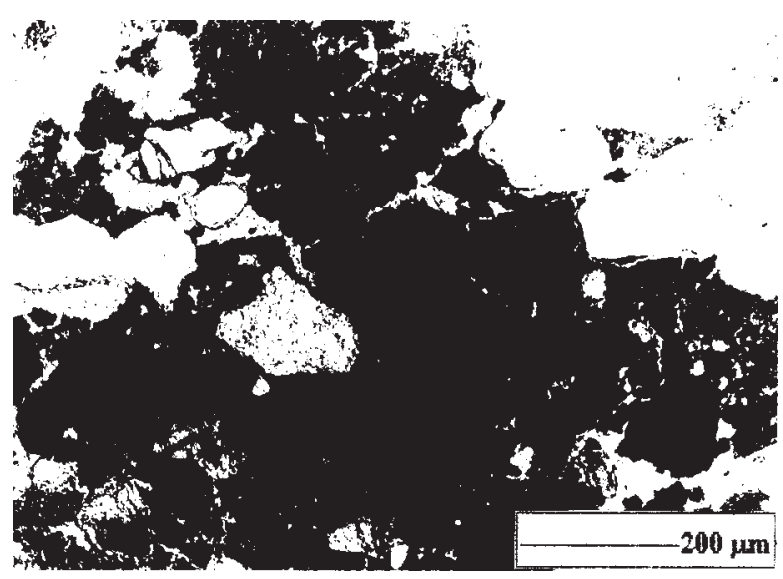

Figura 7. Microporos descontínuos e microfissuras não-comunicantes no horizonte $A B$ do perfil com 18 anos de cultivo (XPL).

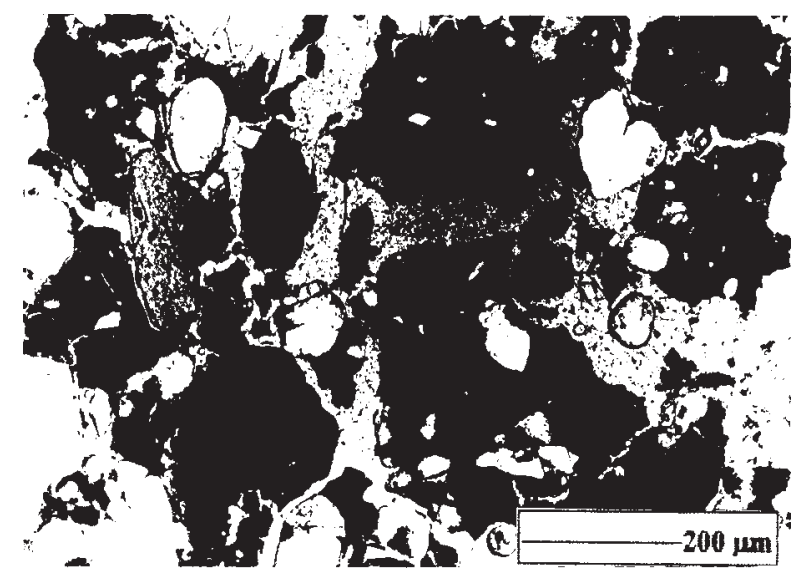

Figura 8. Microfissuras não-comunicantes no horizonte AB do perfil com $\mathbf{2 5}$ anos de cultivo (XPL). 
Quadro 1. Características físicas e químicas dos quatro perfis estudados ${ }^{(1)}$

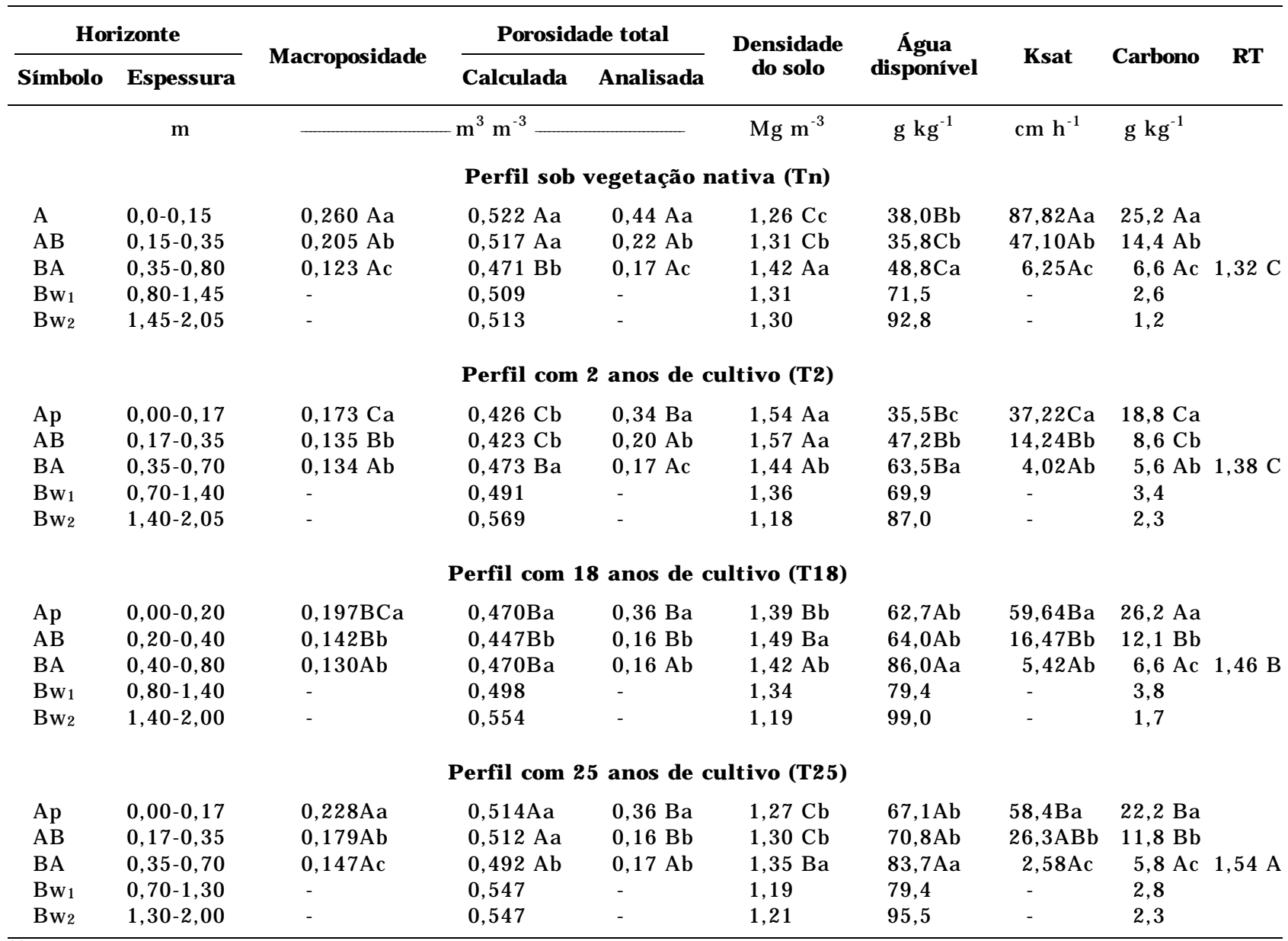

${ }^{(1)}$ Ksat = condutividade hidráulica saturada; e RT = relação textural.

Letras maiúsculas comparam tempos de cultivos na mesma profundidade. Letras minúsculas comparam profundidades dentro do mesmo tempo de cultivo. Médias seguidas de letras iguais não diferem entre si pelo teste de Tukey a $5 \%$.

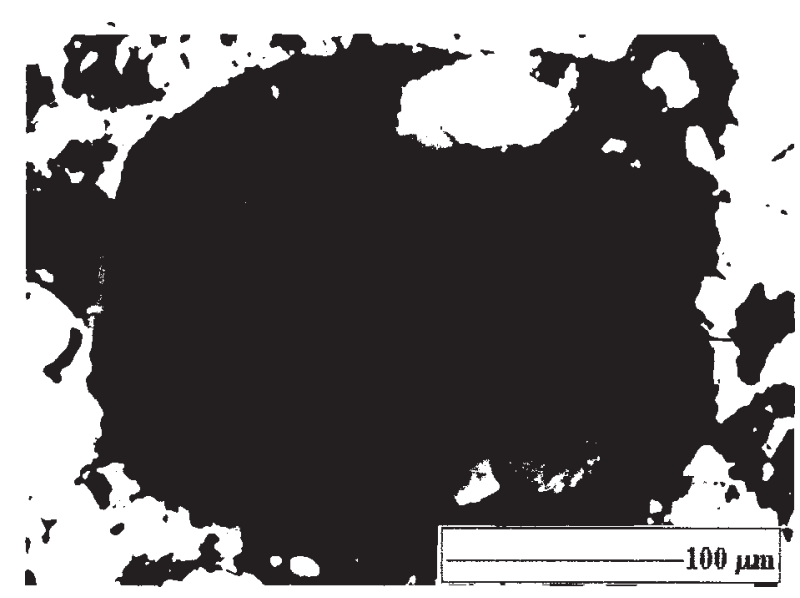

Figura 9. Macroagregados orgânicos do horizonte A do perfil sob mata nativa intei ramente rodeados por poros largos (XPL).

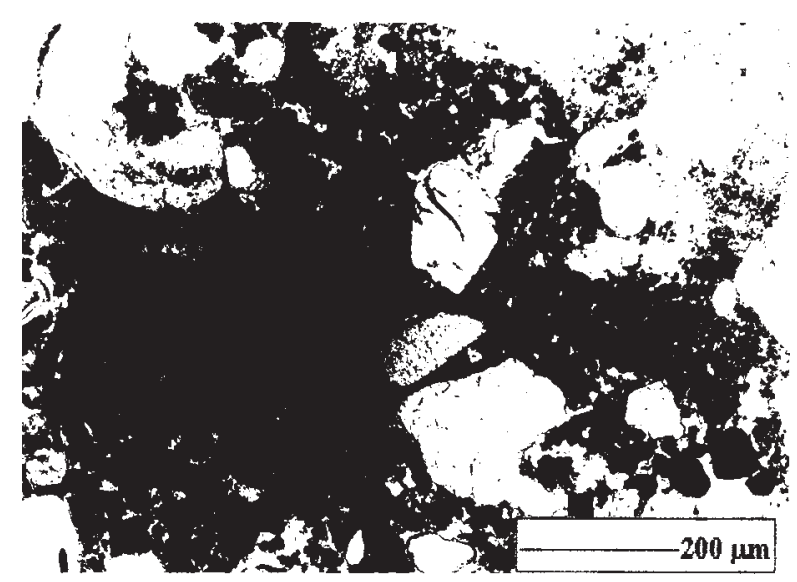

Figura 10. Macroagregados parcialmente destruídos no horizonte Ap do perfil com dois anos de cultivo (XPL). 


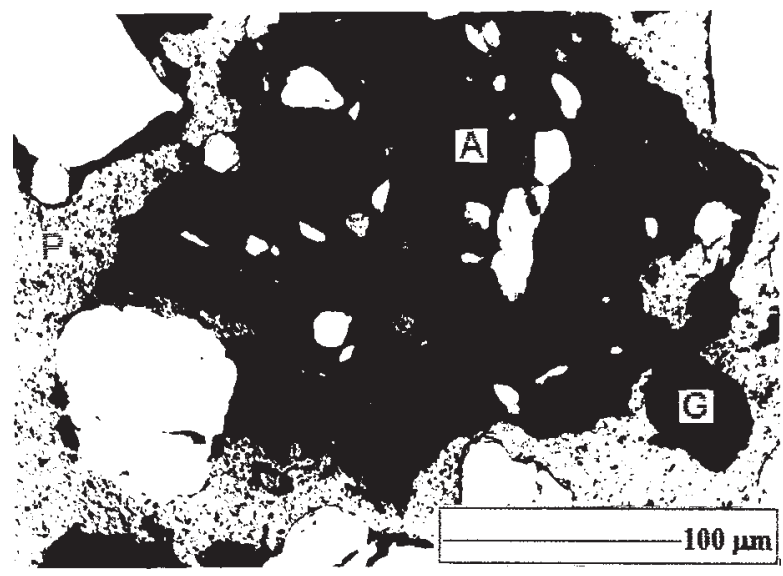

Figura 11. Agregados constituídos de plasma orgânico e inorgânico do horizonte Ap do perfil sob 18 anos de cultivo. P (poro), A (agregado), G (grão de esqueleto) (1/2 XPL).

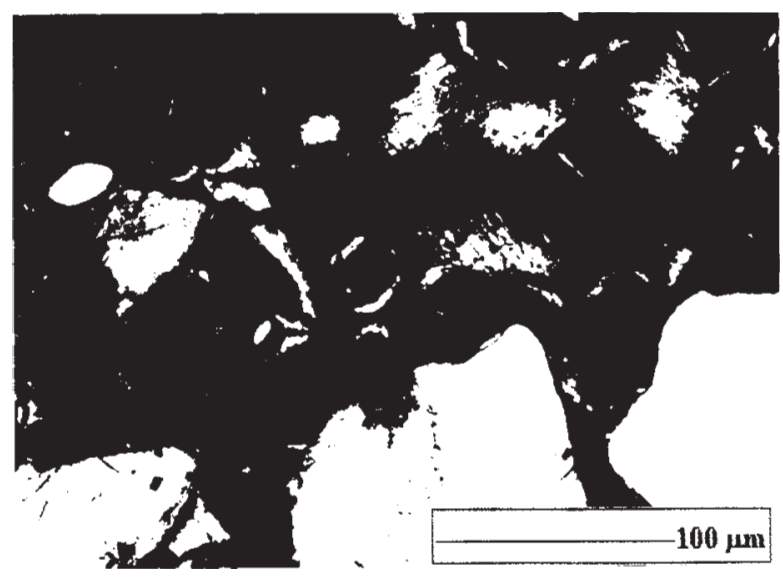

Figura 12. Argilas de iluviação microlaminadas e crescentiformes no horizonte BA do perfil sob 25 anos de cultivo (XPL).

O horizonte A do perfil sob mata nativa apresentou poros de empacotamento compl exo entre os agregados e grãos, os quais são reduzidos no horizonteAp do perfil T2, havendo uma recuperação nos perfis T18 eT25 (Quadro 2).

A porosidade total obtida pelo analisador de imagem nas fotografias das lâminas delgadas (Quadro 1) corrobora sensível redução da porosidade no horizonte superficial com a introdução do cultivo (perfil T2) e mostra também que esta ten dência não aumenta com os anos de cultivo, observando-se ligeiroacréscimo nos perfis T18 eT25 em relaçãoao perfil T2. Revela também que a porosidade do horizonte BA é baixa, comprovando o caráter pedogenético do adensamento deste horizonte.

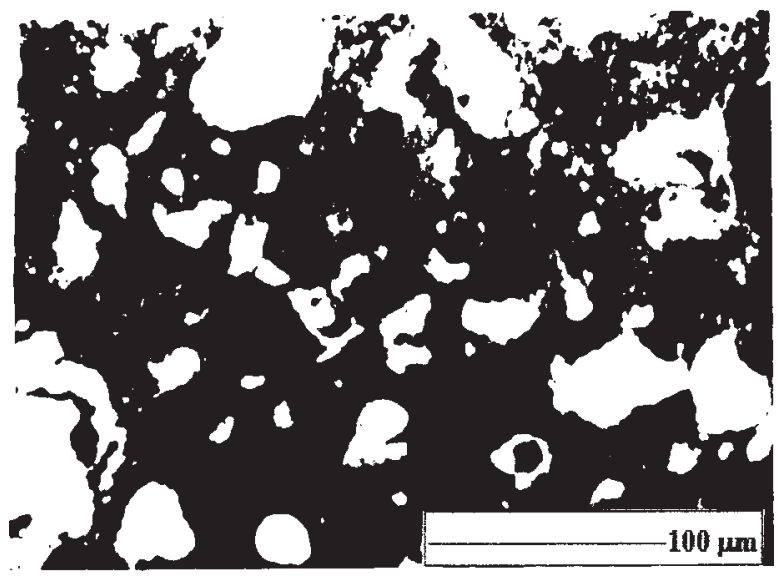

Figura 13. Preenchimento de poros com argila iluvial no horizonte $B A$ do perfil com dois anos de cultivo (XPL).

A figura 12 mostra fei ção pedol ógica representada por argilãs de iluviação microlaminados e crescentiformes, com padrões de extinção fortes no horizonte BA do perfil T25, ocorrendo o mesmo fenômeno nos perfis Tn, T2 eT18 (Quadro 2). Notase redução da porosidade nos horizontes $B A$ em relação aos horizontes $A B$, em conseqüência do preenchimento de poros com argila iluvial (Figura 13). I sto comprova que o solo, além da compactação mecânica verificada nos horizontes AB dos perfis T2 eT18, quefoi evidenciada pelo aumento da densidade do solo, apresenta um adensamento pedogenético natural no horizonte BA, pois o fenômeno ocorre também no perfil sob vegetação nativa (Quadro 2).

Os revestimentos de grãos e os preenchimentos de poros com argila iluvial, mais evidentes nos horizontes BA dos perfis cultivados, evidenciam que o aumento significativo da rel ação textural verificado nesses solos (Quadro 1) não se trata apenas de um fenômeno de empobrecimento dos horizontes superficiais, mas de uma possível formação de horizonte B textural com o tempo, como conseqüência da iluviação de argila para horizontes inferiores. Tal fenômeno foi, provavelmente, acel erado em decorrência da dispersão da argila na movimentação do sol o sob o cultivo contínuo da canade-açúcar.

Alguns trabalhos também revelam que o movimento deargila para horizontes subsuperficiais se dá em razão da sua dispersão. A pulverização dos horizontes superficiais, em decorrência do cultivo contínuo e sob condições de chuva, propicia a eluviação da argila dispersa, levando à conseqüente obstrução dos poros (Helalia et al., 1988; Fuller et al., 1995). Podem também ocorrer penetrações de argila através de finos canais secundários formados pel o avanço do crescimento de raízes de plantas com sistema radicular fasciculado (Cockroft et al., 1969), comoéo caso da cana-de-açúcar no presentetrabal ho. 
Quadro 2. Características micromorfológicas dos quatro perfis estudados

\begin{tabular}{|c|c|c|c|c|c|}
\hline Horizonte & Profundidade & Contextura matricial & Microestrutura & Porosidade & Estruturas associadas \\
\hline \multicolumn{6}{|c|}{ Perfil sob vegetação nativa (Tn) } \\
\hline A & $0,0-0,15$ & $\begin{array}{l}\text { Predomina porfírica } \\
\text { aberta; algumas áreas com } \\
\text { gefúrica }\end{array}$ & $\begin{array}{l}\text { Granular, formada por } \\
\text { macro }(0,1-0,5 \mathrm{~cm}) \mathrm{e} \\
\text { microagregados }(10-50 \mu \mathrm{m}) \\
\text { também ocorre estrutura } \\
\text { em grumos }\end{array}$ & $\begin{array}{l}\text { Empacotamento } \\
\text { complexo com poros } \\
\text { largos entre os } \\
\text { macroagregados; poros } \\
\text { aplanados retos dentro } \\
\text { dos macroagregados; } \\
\text { algumas cavidades }\end{array}$ & $\begin{array}{l}\text { Matéria orgânica em } \\
\text { diferentes estádios de } \\
\text { decomposição influenciando a } \\
\text { cor da matriz. Presença de } \\
\text { fragmentos queimados }\end{array}$ \\
\hline AB & $0,15-0,35$ & $\begin{array}{l}\text { Predomina enáulica; } \\
\text { algumas áreas com } \\
\text { porfírica aberta }\end{array}$ & $\begin{array}{l}\text { Complexa: esponjosa; } \\
\text { microagregados } \\
\text { intergranulares e grumos }\end{array}$ & $\begin{array}{l}\text { Empacotamento } \\
\text { complexo; algumas } \\
\text { cavidades }\end{array}$ & $\begin{array}{l}\text { Matéria orgânica em } \\
\text { diferentes estádios de } \\
\text { decomposição }\end{array}$ \\
\hline BA & $0,35-0,08$ & $\begin{array}{l}\text { Predomina porfírica aberta; } \\
\text { algumas áreas com } \\
\text { enáulica }\end{array}$ & $\begin{array}{l}\text { Complexa: esponjosa e } \\
\text { microagregados } \\
\text { intergranulares }\end{array}$ & $\begin{array}{l}\text { Empacotamento } \\
\text { complexo; al guns poros } \\
\text { preenchidos com argila } \\
\text { iluvial }\end{array}$ & $\begin{array}{l}\text { Teor de matéria orgânica é } \\
\text { reduzido em relação ao } \\
\text { horizonte AB. Argilãs iluviais } \\
\text { microlaminadas e } \\
\text { crescentiformes com padrões } \\
\text { de extinção fortes }\end{array}$ \\
\hline \multicolumn{6}{|c|}{ Perfil com 2 anos de cultivo (T2) } \\
\hline Ap & $0,0-0,17$ & $\begin{array}{l}\text { Predomina enáulica; } \\
\text { algumas áreas com } \\
\text { porfírica aberta }\end{array}$ & $\begin{array}{l}\text { Complexa: microagregados } \\
\text { intergranulares e esponjosa }\end{array}$ & $\begin{array}{l}\text { Empacotamento } \\
\text { complexo }\end{array}$ & $\begin{array}{l}\text { Matéria orgânica em } \\
\text { diferentes estádios de } \\
\text { decomposição influenciando a } \\
\text { cor da matriz. Presença de } \\
\text { fragmentos queimados }\end{array}$ \\
\hline AB & $0,17-0,35$ & $\begin{array}{l}\text { Predomina enáulica; } \\
\text { algumas áreas com } \\
\text { porfírica aberta }\end{array}$ & $\begin{array}{l}\text { Complexa: microagregados } \\
\text { intergranulares e esponjosa }\end{array}$ & $\begin{array}{l}\text { Empacotamento } \\
\text { complexo; al guns poros } \\
\text { preenchidos com argila } \\
\text { iluvial }\end{array}$ & $\begin{array}{l}\text { Matéria orgânica em } \\
\text { diferentes estádios de } \\
\text { decomposição }\end{array}$ \\
\hline BA & $0,35-0,70$ & $\begin{array}{l}\text { Predomina porfírica aberta; } \\
\text { algumas áreas com } \\
\text { enáulica }\end{array}$ & $\begin{array}{l}\text { Complexa: esponjosa e } \\
\text { microagregados } \\
\text { intergranulares }\end{array}$ & $\begin{array}{l}\text { Empacotamento } \\
\text { complexo; al guns poros } \\
\text { preenchidos com argila } \\
\text { iluvial }\end{array}$ & $\begin{array}{l}\text { Teor de matéria orgânica é } \\
\text { reduzido em relação ao } \\
\text { horizonte } A B \text {; argilãs iluviais } \\
\text { mi crolaminadas e } \\
\text { crescentiformes com padrões } \\
\text { de extinção fortes }\end{array}$ \\
\hline \multicolumn{6}{|c|}{ Perfil com 18 anos de cultivo (T 18) } \\
\hline Ap & $0,0-0,20$ & $\begin{array}{l}\text { Predomina enáulica; } \\
\text { algumas áreas com } \\
\text { porfírica aberta }\end{array}$ & $\begin{array}{l}\text { Complexa: microagregados } \\
\text { intergranulares e } \\
\text { esponjosa; presença de } \\
\text { macroagregados } \\
(0,1-0,5 \mathrm{~cm})\end{array}$ & $\begin{array}{l}\text { Empacotamento } \\
\text { complexo }\end{array}$ & $\begin{array}{l}\text { Matéria orgânica em } \\
\text { diferentes estádios de } \\
\text { decomposição }\end{array}$ \\
\hline $\mathbf{A B}$ & $0,20-0,40$ & $\begin{array}{l}\text { Predomina enáulica; } \\
\text { algumas áreas com } \\
\text { porfírica aberta }\end{array}$ & $\begin{array}{l}\text { Complexa: fissurada e } \\
\text { microagregados } \\
\text { intergranulares }\end{array}$ & $\begin{array}{l}\text { Empacotamento } \\
\text { complexo alguns poros } \\
\text { aplanados em zig-zag e } \\
\text { curvos; alguns poros } \\
\text { preenchidos com argila } \\
\text { iluvial }\end{array}$ & $\begin{array}{l}\text { Matéria orgânica em } \\
\text { diferentes estádios de } \\
\text { decomposição }\end{array}$ \\
\hline BA & $0,20-0,40$ & $\begin{array}{l}\text { Predomina porfírica } \\
\text { fechado; algumas áreas } \\
\text { porfírica aberta }\end{array}$ & $\begin{array}{l}\text { Complexa: esponjosa e } \\
\text { microagregados } \\
\text { intergranulares }\end{array}$ & $\begin{array}{l}\text { Empacotamento } \\
\text { complexo. Muitos poros } \\
\text { preenchidos com argila } \\
\text { iluvial }\end{array}$ & $\begin{array}{l}\text { Teor de matéria orgânica é } \\
\text { reduzido em relação ao } \\
\text { horizonte AB. Argilãs iluviais } \\
\text { microlaminadas e } \\
\text { crescentiformes com padrões } \\
\text { de extinção fortes }\end{array}$ \\
\hline \multicolumn{6}{|c|}{ Perfil com 25 anos de cultivo (T25) } \\
\hline Ap & $0,0-0,17$ & $\begin{array}{l}\text { Predomina enáulica; } \\
\text { algumas áreas com } \\
\text { porfírica aberta }\end{array}$ & $\begin{array}{l}\text { Complexa: microagregados } \\
\text { intergranulares, esponjosa } \\
\text { e fissurada }\end{array}$ & $\begin{array}{l}\text { Empacotamento } \\
\text { complexo e poros } \\
\text { aplanados enviesados }\end{array}$ & $\begin{array}{l}\text { Matéria orgânica em } \\
\text { diferentes estádios de } \\
\text { decomposição influenciando a } \\
\text { cor da matriz }\end{array}$ \\
\hline AB & $0,17-0,35$ & $\begin{array}{l}\text { Predomina enáulica; } \\
\text { algumas áreas com } \\
\text { porfírica aberta }\end{array}$ & $\begin{array}{l}\text { Complexa: fissurada e } \\
\text { microagregado s } \\
\text { intergranulares }\end{array}$ & $\begin{array}{l}\text { Empacotamento } \\
\text { complexo e poros } \\
\text { aplanados curvos e em } \\
\text { zig-zag. Alguns poros } \\
\text { preenchidos com argila } \\
\text { iluvial }\end{array}$ & $\begin{array}{l}\text { Matéria orgânica em } \\
\text { diferentes estádios de } \\
\text { decomposição. Argilas iluviais } \\
\text { microlaminadas e } \\
\text { crescentiformes com padrões } \\
\text { de extinção fortes }\end{array}$ \\
\hline BA & $0,35-0,70$ & $\begin{array}{l}\text { Predomina porfírica } \\
\text { fechado }\end{array}$ & $\begin{array}{l}\text { Complexa: esponjosa e } \\
\text { microagregados } \\
\text { intergranulares }\end{array}$ & $\begin{array}{l}\text { Empacotamento } \\
\text { complexo. Muitos poros } \\
\text { preenchidos com argila } \\
\text { iluvial }\end{array}$ & $\begin{array}{l}\text { Matéria orgânica em } \\
\text { diferentes estádios de } \\
\text { decomposição. Argilãs iluviais } \\
\text { microlaminadas e } \\
\text { crescentiformes com padrões } \\
\text { de extinção fortes. }\end{array}$ \\
\hline
\end{tabular}




\section{CONCLUSÕES}

1. O primeito plantio da cana-de-açúcar comprometeu a macroestrutura, a densidade do solo, a condutividade hidráulica e o carbono orgânico dos horizontes superficiais do solo, havendo uma recuperação substancial após 18 e 25 anos de cultivo.

2. As análises micromorfológicas mostraram evidências de que, além do desenvolvimento inicial de compactação nos horizontes $A p$ e $A B$, ocorreu um adensamento pedogenético natural do sol o no horizonte BA, o qual foi acelerado com o cultivo da canade-açúcar, pelo preenchimento de poros com argila iluvial.

3. Apesar de não ter sido observada macromorfologicamente presença decerosidade, a mi cromorfol ogia observou feições pedológicas constituídas por argilãs de iluviação e preenchimento de poros com argila iluvial, que evidenciam uma tendência à formação de horizonte $\mathrm{B}$ textural, nesses solos, com o tempo.

\section{LITERATURA CITADA}

BREWER, R. Fabric and mineral analysis of soils. New York, J ohn Wiley, 1964. p.

BREWER, R. \& PAWLUK, S. Investigations of some soils developed in hummocks of the Canadian sub-artic and southernartic regions. 1. Morphology and micromorphology. Can. J. Soil Sci., 55:301-319, 1975.

BULLOCK, P.; FEDOROFF, N.; J ONGERIUS, A.; STOOPS, G.; TURSINA, T. \& BABEL, U. Handbook for soil thin section description. Albrington, Reino Unido. Waine Reserch, 1985. $152 \mathrm{p}$.

CAGAUAN, B. \& UEHARA, G. Soil anisotropy and its relation to aggregatestability. Soil Sci. Soc. Am. Proc., 29:198-200, 1965.

CERRI, C.C.; FELLER, C. \& CHAUVEL, A. Evolução das principais propriedades de um Latossolo Vermel ho-Escuro após desmatamento e cultivo por doze e cinquenta anos com cana-de-açucar. Cahiers Orstom, sér. Pédologie, 26:3750, 1991.

COSTA LIMA, J.M.J . \& COSTA LI MA, V. Modificações na trama e morfologia dos poros do solo pelo efeito do cultivo. In: CONGRESSO BRASILEIRO DE CIÊNCIA DO SOLO., 25., Viçosa, 1995. Resumos Expandidos. Viçosa, Sociedade Brasileira de Ciência do Solo, 1995. v.3. p.1679-1671.

COCKROFT, B.; BARLEY, K.P. \& GREACEN, E.L. The penetration of clays by fine probes and root tips. Aust. J. Soil Res., 7:333-348, 1969.

DREES, L.R.; KARATHANASIS, A.D.; WILDING, L.P. \& BLEVINS, R.L. Micromorphological characteristics of longterm no-till and conventionally tilled soils. Soil Sci. Soc. Am. J., 58:508-517, 1994.

EMPRESA BRASILEIRA DE PESQUISA AGROPECUÁRIAEMBRAPA. Serviço Nacional de Conservação e Levantamento de Solos. Manual de métodos de análises do solos. Rio de J aneiro, 1979. 247p.
FITZPATRICK, E.A. The micromorphology of soil. Aberdeen, University of Aberdeen, 1984. 433p.

FULLER, L.G.; GOH, T.B. \& OSCARSON, D.W. Cultivation effects on dispersible clay of soil aggregates. Can. J. Soil Sci., 75:101-107, 1995.

GROHMANN, F. Distribuição e tamanho de poros em três tipos de solos do estado de São Paulo. Bragantia, 19:319-329. 1960.

HELALIA, A.M.; LETEY, J \& \& GRAHAM, R.C. Crust formation and clay migration effects on infiltration rate. Soil Sci. Soc. Am. J., 52:251-255, 1988.

J ONGERIUS, A. \& HEINTZBERGER, G. The preparation of mammoth-sized thin sections. Wageninger, Soil Survey Institute, 1963. p.3-37. (Soil Survey Paper, 1)

J ONGERIUS, A.; SCHOODERBEEK, D.; JAGER, A. \& KOWALINSKI, ST. Electro-optical soil porosity investigation by means of quantimet-B equipament. Geoderma, 7:177-198, 1972.

KLUTE, A. \& DIRKSEN, C. Hydraulic conductivity and difusivity: laboratory methods. In: KLUTE, A., ed. Methods of soil analysis; physical and mineralogical methods. Madison, American Society of Agronomy, 1986. p.687-734. (Part I)

LIMA, L.R.F. Determinação da condutividadehidráulica saturada em solos aluvionais por método de campo e laboratório. Recife, Universidade Federal Rural de Pernambuco, 1986. 81p. (Tese de Mestrado)

LIMA, P.C.; CURI, N. \& LEPSCH, I.F. Terminologia de micromorfologia do solo. B. Inf. SBCS, 10:33-43, 1985.

MURPHY, C.P. Thin section preparation of soils and sediments. Berkhanmsted, Academic Publis., 1986. 145p.

OADES, J.M. Soil organic matter and structural stability: mechanisms and implications for management. Plant Soil, 76:319-337, 1984.

ORTOLANI,A.F.; COAN, O.; BENINCASA, M.; BANZATTO, D.A.; GAMERO, C.A. \& NATALE, W. Manejo do solo agrícola durante dez anos com a cultura do milho (Zea mays, L.) I: Efeitos no solo. In: CONGRESSO BRASILEIRO DE ENGENHARIA AGRÍ COLA, 20., Londrina, 1991. Anais. Londrina, Sociedade Brasileira de Engenharia Agrícola, 1991. p.43.

PAGLIAI, M.; La MARCA, M. \& LUCAMANTE, G. Micromorphometric and micromorphological investigations of a clay loam soil in viticulture under zero and conventional tillage. J. Soil Sci., 34:391-403, 1983.

PAWLUK, S. Micromorphological investigations of cultivated gray Luvisols under different management practices. Can. J. Soil Sci., 60:731-745, 1980.

SANTOS, M.C.; MERMUT, A.R. \& RIBEIRO, M.R. Micromorfologia de solos com argila de atividade baixa no sertão de Pernambuco. R. bras. Ci. Solo, 15:83-91, 1991.

SCHAEFER，C.E.R.; LIMA，P.C. \& DUARTE, M.N. Micromorfologia de horizontes $B$ de Latossolos brasileiros. In: CONGRESSO BRASILEIRO DE CIÊNCIA DO SOLO., 25., Viçosa, 1995. Resumos Expandidos. Viçosa, Sociedade Brasileira de Ciência do Solo, 1995. p.1610-1612.

SHIPITALO, M.J . \& PROTZ, R. Comparison of morphology and porosity of a soil under conventional and zero tillage. Can. J. Soil Sci., 67:445-456, 1987. 
SILVA, J .A.A. \& SILVA, I.P. Estatística experimental aplicada à ciência florestal. Recife, Universidade Federal Rural de Pernambuco, 1982. 294 p.

STOOPS, G.J . \& BUOL, S.W. Micromorphology of Oxisols. In: DOUGLAS, L.A. \& THOMPSON, M.L., eds. Soil micromorphol ogy and soil classification. Madison, Soil Science Society of America, 1985. p.105-119 (Special Publication, 15)

STOOPS, G.J. \& JONGERIUS, A. Proposal for a micromorphological classification of soil materials. I. A classification of related distribution of coarse and fine particles. Geoderma, 13:189-200, 1975.
TISDALL, J .M. \& OADES, J .M. Organic matter and water-stable aggregates in soils. J. Soil Sci., 33:141-163, 1982.

VOMOCIL, J .A. Porosity. In: BLACK, C.A., ed. Methods of soil analysis; physical and mineralogical properties, including statistics of measurement and sampling. Madison, America Society Agronomy, 1965. 191p.

ZONTA, E.P. \& MACHADO, A.A. SANEST - Sistema deAnálise Estatística. São Paulo, Escola Superior deAgricultura Luiz de Queiroz, 1980. (Software) 